\title{
The Level of Knowledge About Radiation Safety and the Frequency of the Use of Protective Equipment Among Healthcare workers Exposed to Radiation in Different Units
}

\author{
다) Seher KURTUL, ${ }^{\circledR}$ Neslihan KURTUL² \\ 'Department of Occupational Health and Occupational Diseases, Ege University School of Medicine, İzmir-Turkey \\ ${ }^{2}$ Department of Radiation Oncology, Kahramanmaraş Sütçü İmam University School of Medicine, Kahramanmaraş-Turkey
}

\begin{abstract}
OBJECTIVE
We aimed to investigate the level of knowledge about radiation safety, the frequency of the use of protective equipment, and the reasons for not using it among healthcare workers.
\end{abstract}

\section{METHODS}

The data were collected by administering a standard cross-sectional survey via the internet to 443 healthcare workers exposed to radiation. The chi-square test was used to compare groups.

\section{RESULTS}

The median age of participants was 30 years, and $52.8 \%$ were females. Participants comprised radiology (61.4\%), radiation oncology (21.4\%), cardiology (7.2\%), fluoroscopy use (5.9\%), and nuclear medicine (4.1\%) workers. In total, $90.1 \%$ of the workers had dosimeters. Of those who used fluoroscopy, only $11.5 \%$ had dosimeters. A total of $20.3 \%$ of the workers stated that dosimetry is reliable, and $89.7 \%$ of the workers in the cardiology and fluoroscopy use groups knew that they had to wear lead aprons $(\mathrm{p}<0.05)$. The rate of thyroid protector use was $100 \%$ in the cardiology group, whereas $23.1 \%$ of the fluoroscopy use group did not use a thyroid protector and $7.7 \%$ were not aware of its presence $(\mathrm{p}<0.05)$. Additionally, the protective goggles use in all groups was $6.3 \%$. Of the workers, $20.8 \%$ believed in the protection of protective equipment. The most common reason for not using protective equipment was the restraint of mobility capability.

\section{CONCLUSION}

Exposure to radiation is an important issue in terms of work health and occupational diseases. For this reason, workers' knowledge about radiation safety and protective equipment should be increased, and the hospital administration should inspect the implementation of protective measures regularly.

Keywords: Health worker; ionized radiation; protective equipment.

Copyright $\odot$ 2018, Turkish Society for Radiation Oncology

\section{Introduction}

Radiation is energy emitted in the form of electromagnetic waves or particles from a source. It is of two kinds based on its effect on matter: ionizing and non- ionizing radiation. People are exposed to various types of occupational ionizing radiation in several areas of work, such as industry, medicine, education, research, and atomic energy and fuel production.[1] Radiation came into use in the medical field with the discovery of 
X-rays by Röntgen in 1895 and radioactivity by Marie Curie in the early $20^{\text {th }}$ century. It has been used increasingly more often in medical imaging and treatment procedures thanks to newly developed technologies.[2]

Today, a great majority of artificial radiation sources are used in medical fields, most of which are used for diagnostic radiological examinations. [3] Based on the 2008 World Health Organization report, 20\% of human radiation exposure is due to medical use. Likewise, 3.6 billion X-rays, 37 million nuclear medicine applications, and 7.5 million radiotherapy treatments are provided worldwide annually.[4] Studies have found that the number of tomography examinations has increased by 12 -fold in the United Kingdom and by 20 -fold in the United States in the last two decades. [5] Alongside the continuous development and ever-increasing use of modern medical technologies, healthcare workers are exposed to undesirable and unnecessary radiation doses.

In hospitals, exposure to radiation is the most common among healthcare workers working in the departments of radiology, radiation oncology, nuclear medicine, and invasive cardiology and in those working with fluoroscopy.

The health effects of radiation can manifest at different times and in various ways depending on the dose and the characteristics of the irradiated parts of the body. It is well known that even very low doses of radiation are carcinogenic and detrimental to the skin, eyes, gonads, and blood cells.[6] The effects of chronic or intermittent exposure to radiation at low doses over a long period of time may emerge years later. This is a serious risk factor for healthcare workers exposed to radiation.[7]

The awareness and attitude of healthcare workers exposed to radiation are very important for ensuring the safety of patients and healthcare workers. Since healthcare workers are constantly working in such an environment and apply radiation for medical purposes, their knowledge, attitude, and behavior about the effects of ionizing radiation on human health are important. The use of personal monitoring and protective equipment is also an important part of workers' protection from the harmful effects of ionizing radiation.

In the present study, we aimed to determine the level of knowledge about radiation safety and the frequency of the use of protective equipment among healthcare workers exposed to radiation in various departments and units and to suggest solutions for the problems encountered.

\section{Materials and Methods}

The present study included all healthcare workers in the departments of radiology, radiation oncology, nuclear medicine, and invasive cardiology and those working with fluoroscopy, including those in public and private hospitals. A questionnaire comprising 23 questions was prepared to assess their level of knowledge about radiation safety, their frequency of the use of protective equipment, and the reasons if such equipment was not used. The first eight questions collected their demographic data, occupation, work experience, and working conditions. The remaining questions were about the level of participants' radiation exposure, knowledge about the negative effects of radiation on health, attitude toward radiation safety, reasons for not using personal protective equipment, and sources of information about radiation safety. No study sample was selected for this study; all healthcare workers with radiation exposure who were accessible via the internet were included. Participating healthcare workers filled in the standard cross-sectional questionnaire prepared by the researcher online on a voluntary basis. This study was approved by the ethics committee of Kahramanmaras Sütçü İmam University School of Medicine (2017/21, No: 18). A total of 443 personnel responded to the calls to participate and were included in the present study. The data were analyzed using the SPSS 18.0 program; the chi-square test was used for the statistical analysis of the differences between the groups. The level of significance was set at $\mathrm{p}<0.05$.

\section{Results}

Of the participants, $46.7 \%$ were males $(n=207)$ and $52.8 \%$ were females $(n=234)$. The median age of the surveyed personnel was 30 (min: 19, max: 61) years; the 26-35 age group was the largest age group (40\%). Of the participants, $65 \%$ were exposed to radiation for 10 years or less. The numbers of participating healthcare workers by department were as follows: 272 from radiology, 95 from radiation oncology, 32 from cardiology, 26 from the operating room (fluoroscopy), and 18 from nuclear medicine. The numbers by occupation categories were as follows: 330 technicians, 42 physicians, 38 radiation physicists, 32 nurses/physician's assistants, and one service personnel. A significant proportion of employees (69.3\%) were exposed to radiation more than once a day. The demographic and occupational data are given in Table 1.

The healthcare workers were also asked about whether they knew the legal working hours per month; 
Table 1 Demographic and occupational data

\begin{tabular}{|c|c|c|}
\hline & $\begin{array}{c}\text { Number } \\
\text { (N) }\end{array}$ & $\begin{array}{c}\text { Percentage } \\
(\%)\end{array}$ \\
\hline \multicolumn{3}{|l|}{ Gender } \\
\hline Male & 207 & 46.7 \\
\hline Female & 234 & 52.8 \\
\hline \multicolumn{3}{|l|}{ Age } \\
\hline $19-25$ & 136 & 30.7 \\
\hline $26-35$ & 177 & 40 \\
\hline $36-45$ & 97 & 21.9 \\
\hline 46 and above & 33 & 7.4 \\
\hline \multicolumn{3}{|l|}{ Department } \\
\hline Radiology & 272 & 61.4 \\
\hline Radiation oncology & 95 & 21.4 \\
\hline Nuclear medicine & 18 & 4.1 \\
\hline Cardiology & 32 & 7.2 \\
\hline Operating room (Fluoroscopy) & 26 & 5.9 \\
\hline \multicolumn{3}{|l|}{ Occupation } \\
\hline Technician & 330 & 74.5 \\
\hline Radiation physicist & 38 & 8.6 \\
\hline Nurse/physician's assistant & 32 & 7.2 \\
\hline Physician & 42 & 9.5 \\
\hline Service personnel & 1 & 0.2 \\
\hline \multicolumn{3}{|l|}{ Duration of Radiation Exposure } \\
\hline 10 year or below & 288 & 65 \\
\hline 10 year and above & 155 & 35 \\
\hline \multicolumn{3}{|l|}{ Frequency of Radiation Exposure } \\
\hline More than once a day & 307 & 69.3 \\
\hline Once a week & 22 & 5 \\
\hline More than once a week & 95 & 21.4 \\
\hline Once a month & 9 & 4.3 \\
\hline
\end{tabular}

Table 2 Use of and trust in dosimeters

\begin{tabular}{|c|c|c|}
\hline & $\begin{array}{l}\text { Number } \\
\text { (N) }\end{array}$ & $\begin{array}{c}\text { Percentage } \\
\text { (\%) }\end{array}$ \\
\hline \multicolumn{3}{|c|}{ Do you have a dosimeter? } \\
\hline Yes & 399 & 90.1 \\
\hline No & 44 & 9.9 \\
\hline \multicolumn{3}{|c|}{$\begin{array}{l}\text { How frequently do you wear the } \\
\text { dosimeter? }\end{array}$} \\
\hline Every day & 316 & 71.3 \\
\hline A few days a week & 48 & 10.8 \\
\hline A few days a month & 7 & 1.6 \\
\hline Never & 28 & 6.3 \\
\hline \multicolumn{3}{|c|}{ Do you trust dosimeter readings? } \\
\hline Yes, I trust & 90 & 20.3 \\
\hline No, I do not trust & 273 & 61.6 \\
\hline No idea & 80 & 18.1 \\
\hline
\end{tabular}

it was found that $84.9 \%$ knew about their rights, $10.6 \%$ did not know, and $4.5 \%$ were not sure. Of the partici- pants, $90.1 \%$ had a dosimeter. There was no significant difference between the occupational categories in terms of having a dosimeter. However, $40.6 \%$ of the nurses/physician's assistants and only $11.5 \%$ of the personnel working with fluoroscopy had a dosimeter. Of those who had a dosimeter, $71.3 \%$ wear it daily but $6.3 \%$ never wear it. Only $20.3 \%$ of the personnel trusted the dosimeter readings (Table 2).

Of the participants, $86.2 \%$ stated that they had received training about the health hazards of radiation. In line with this, when asked about the health hazards of radiation, $61.2 \%$ were aware of the acute symptoms, such as nausea and vomiting; $90.5 \%$ were aware of skin disorders; $80.1 \%$ were aware of cataract; $64.1 \%$ were aware of bone marrow suppression; $77.4 \%$ were aware of infertility; $72.7 \%$ were aware of congenital malformations; $93.2 \%$ were aware of secondary cancers; and $67.7 \%$ were aware of radiation-related death. Likewise, when asked about the sensitivity of organs to radiation damage, $91.4 \%$ indicated that reproductive organs are susceptible, $42.7 \%$ indicated that nerve tissue is resistant, $85.3 \%$ indicated that the eye lens is sensitive, $59.8 \%$ indicated that muscular tissue is resistant, and $31.2 \%$ indicated that the spleen is sensitive.

The participants were also asked about what types of personal protective equipment were available in their departments. The most and least commonly available gears were lead aprons (88.3\%) and lead gloves (22.1\%), respectively. Thyroid protectors were available in $79.7 \%$ of the departments; however, $7.7 \%$ of the personnel working with fluoroscopy were not aware of its presence.

The frequency of the use of these protective gears was as follows: lead shield, $50.6 \%$; lead aprons, $39.7 \%$; thyroid protector, $36.6 \%$; protective goggles, $5.2 \%$; and lead gloves, $2.9 \%$.

In a comparison of the personnel working in the cardiology unit with those working in nuclear medicine and fluoroscopy units, where there is direct exposure to radiation, all of the former used thyroid protectors and lead aprons, whereas $34.1 \%$ and $22.7 \%$ of the latter did not use these equipment, respectively. The difference was statistically significant $(\mathrm{p}<0.01)$. The use of safety goggles, lead shields, and lead gloves was more frequent among the medicine and fluoroscopy unit, but the difference was not statistically significant (Table 4).

Among the personnel working in the cardiology unit or with fluoroscopy, there was no significant relationship between the use of lead aprons or protective goggles and gender, marital status, age, occupation, years of exposure to radiation, or training on health effects of radiation. Thyroid protector use was found 
Table 3 Availability of protective equipment by departments

\begin{tabular}{|c|c|c|c|c|c|c|c|c|c|c|}
\hline \multirow[t]{2}{*}{ Department } & \multicolumn{2}{|c|}{ Lead apron } & \multicolumn{2}{|c|}{ Lead shield } & \multicolumn{2}{|c|}{ Thyroid protector } & \multicolumn{2}{|c|}{ Protective goggles } & \multicolumn{2}{|c|}{ Lead gloves } \\
\hline & $\mathbf{N}$ & $\%$ & $\mathbf{N}$ & $\%$ & $\mathbf{N}$ & $\%$ & $\mathbf{N}$ & $\%$ & $\mathbf{N}$ & $\%$ \\
\hline Fluoroscopy & 26 & 100 & 20 & 76.9 & 23 & 88.5 & 4 & 15.4 & 3 & 11.5 \\
\hline Cardiology & 32 & 100 & 17 & 53.1 & 32 & 100 & 25 & 78.1 & 3 & 9.4 \\
\hline Nuclear medicine & 18 & 100 & 18 & 100 & 18 & 100 & 16 & 88.9 & 14 & 77.8 \\
\hline Radiation oncology & 56 & 58.9 & 35 & 36.8 & 3 & 38 & 17 & 17.9 & 13 & 13.7 \\
\hline Radiology & 256 & 95.2 & 233 & 85.7 & 98 & 242 & 112 & 41.2 & 65 & 23.9 \\
\hline Total & 391 & 88.3 & 323 & 72.9 & 353 & 79.7 & 174 & 39.3 & 98 & 22.1 \\
\hline
\end{tabular}

Table 4 Usage of personal protective equipment by departments

\begin{tabular}{|c|c|c|c|c|c|c|c|c|c|c|}
\hline \multirow[t]{2}{*}{ Department } & \multicolumn{2}{|c|}{ Lead shield } & \multicolumn{2}{|c|}{ Lead apron } & \multicolumn{2}{|c|}{ Thyroid protector } & \multicolumn{2}{|c|}{ Protective goggles } & \multicolumn{2}{|c|}{ Lead gloves } \\
\hline & $\mathbf{N}$ & $\%$ & $\mathbf{N}$ & $\%$ & $\mathbf{N}$ & $\%$ & $\mathbf{N}$ & $\%$ & $\mathbf{N}$ & $\%$ \\
\hline Fluoroscopy + Nuclear medicine & 17 & 38.6 & 34 & 77.3 & 29 & 65.9 & 9 & 20.5 & 5 & 11.4 \\
\hline Cardiology & 6 & 18.8 & 32 & 100 & 32 & 100 & 5 & 15.6 & 0 & 0 \\
\hline Total & 23 & 30.3 & 66 & 86.8 & 61 & 80.3 & 14 & 18.4 & 5 & 6.6 \\
\hline
\end{tabular}

to be significantly higher among males than females $(p<0.05)$. However, there was no relationship between thyroid protector use and other variables.

Of the participants, $80.1 \%$ stated that they knew, $16.5 \%$ that they partly knew, and $3.4 \%$ that they did not know when to use personal protective equipment. Similarly, $80.6 \%$ stated that they knew, $15.8 \%$ that they partly knew, and $3.4 \%$ that they did not know how to use protective equipment. Additionally, $20.8 \%$ believed, $73.4 \%$ partially believed, and $5.9 \%$ did not believe in the protective function of such equipment.

Most of the participants learned how to protect themselves from radiation at their school of higher education (91.6\%), followed by in-service training and self-teaching (41.5\%), colleagues (33\%), and workshops organized by Turkish Atomic Energy Authority (TAEK), professional associations, or companies (14.9\%).

The participants were also asked about why they do not use protective equipment; $80.4 \%$ cited restriction of mobility, $61.6 \%$ physical discomfort, $26.4 \%$ disbelief in the adequacy of equipment's protective function, $23.7 \%$ poor material quality among other reasons, whereas $10.8 \%$ did not believe in the necessity of such equipment for the work done, and $10.4 \%$ were not given protective equipment.

\section{Discussion}

The healthcare industry is one of the areas with significant occupational health and safety risks associated with radiation. For this reason, healthcare workers exposed to radiation should have adequate knowledge of radiation safety and access to safety equipment. There are a limited number of studies that evaluate the radiation exposure of healthcare workers in Turkey. The present study is important for determining the level of knowledge about radiation safety and the frequency of the use of protective equipment among healthcare workers.

Depending on the dose and duration, exposure to radiation can cause cellular and chromosomal damage and associated cancers in the skin, thyroid, bone marrow, eye, and gonads. Healthcare workers working with ionizing radiations are regularly and continuously exposed to such radiation. As such, the chronic effects of radiation can be a risk for healthcare workers.[8]

Some tissues and cells are more susceptible to radiation due to their structure and intrinsic properties. Therefore, additional protective equipment is used for susceptible organs or body parts, such as the thyroid, eyes, and gonads. Knowledge of the radiosensitive organs is important for healthcare workers to protect themselves. We found that the participants' knowledge of radiosensitive/radioresistant organs did not significantly change based on the department they work in. However, it is noteworthy that those working with fluoroscopy had less knowledge about the subject.

The use of personal dosimeters by healthcare workers exposed to radiation is required by law.[9] Despite the law, 9.9\% of the participants did not have a dosimeter. The lower rate of dosimeter ownership among the nurses/physician's assistants and staff working with fluoroscopy was because the staff working in the operat- 
ing room was largely composed of nurses. Having a low confidence in the dosimeter readings may be one of the most important factors affecting its use. The dosimeter's sensitivity to the levels of radiation in the working environment is important in this low confidence. Film dosimeters cannot detect low-dose radiation.[10] Recently, thermoluminescence dosimeters have been introduced to overcome this problem.

In previous studies, it has been shown that each part of the body is exposed to radiation at different levels depending on the type of radiation, and the necessity of using the right protective equipment was emphasized.[11] Several measures have been reported to protect against the harmful effects of ionizing radiation. Equipment such as lead goggles, thyroid protectors, lead aprons, etc., is very important in preventing radiation exposure, particularly in fluoroscopic examinations where workers are exposed to direct radiation. [12] In our study, although most of the departments/ units studied were found to have lead aprons, thyroid protectors, and lead shields, they were mostly found to lack lead goggles, lead gloves, and gonadal shields.

The most commonly used protective equipment was lead shields, and the least commonly used was lead gloves. The more common use of the lead shield was because most of the participants were radiology workers, among whom the technicians constituted a very high proportion.

Several studies have shown that wearing lead aprons is an important method of protection from radiation. [13] A lead sheet of $0.5-\mathrm{mm}$ thickness was reported to reduce radiation exposure by $97 \%-99 \%$.[14] In our study, the use of lead aprons was found to be significantly higher in personnel working in the cardiology department and those working with fluoroscopy.

Dawson and Punwani indicated that the thyroid is the most critical organ in terms of radiation damage and that radiation is one of the well-known causes of thyroid cancers. [15] In one study, the incidence of thyroid cancer among healthcare workers was found to be higher than that among the general population.[16] Faulkner et al. reported that the use of lead goggles and thyroid shields significantly reduces eye and thyroid problems due to radiation exposure.[17] In our study, the rate of thyroid protector use was $100 \%$ in the cardiology department. However, it was $53.8 \%$ among the personnel working with fluoroscopy, which was found to be due to the absence of thyroid protector equipment in some of the operating rooms using fluoroscopy. Despite the fact that thyroid protectors are mostly available in radiology units, the low rate of their use might be because the frequency of fluoroscopic procedures in radiology units is less.
In a study comparing groups of physicians in various branches who were and were not exposed to occupational ionizing radiation, Auvinen et al. found that physicians who were exposed to ionizing radiation lost more of their eye lens's transparency.[18] Similarly, Hammer et al.[19] reported that cataracts were more common among physicians who performed fluoroscopic examinations and were exposed to ionizing radiation for a long time and that there was no threshold dose for cataract formation. The use of lead goggles was very low in all departments/units in our study, which was considered to be due to the absence of lead goggles or the lack of using habits.

The hands of healthcare workers who conduct interventional work are directly exposed to X-rays. Singer reported that during operations performed under fluoroscopy guidance, primary radiation exposure is to the hands of the surgeons, with scattered radiation received by the trunk. The healthcare workers were urged to use radiation protection equipment to prevent such exposure.[20] Stoeckelhuber et al. reported that the use of lead gloves alone during procedures performed under fluoroscopy guidance provides a $77 \%$ reduction in exposure. Wearing lead gloves was recommended if it does not prolong the procedure.[21] Another study reported that the use of disposable sterile lead gloves hinders mobility, interventional manipulations, and finger sensitivity due to their thickness. [22] In our study, only $2.9 \%$ of all the participants reported using lead gloves, while those working with fluoroscopy and in invasive cardiology units did not use them at all. The availability of lead gloves in these two groups was $10.3 \%$. The low use of this equipment in these two groups may be due to inaccessibility in the departments/units as well as difficulties in using them, such as decreased mobility and reduced finger sensitivity.

Although most of the participants knew when and how to use protective equipment, only $20.8 \%$ of them believed in the protective function of the equipment. This may be due to the lack of knowledge about the effectiveness of protective equipment.

Most of the participants learned how to protect themselves from radiation at school, which was followed by in-service training (41.5\%), self-education $(41.5 \%)$, colleagues $(33 \%)$, and training sessions organized by TAEK, professional associations, and companies (14.9\%). It was notable that regular institutional on-site training about radiation safety was not sufficient.

The limitation of our study is the possibility that the participants were not unbiased in their responses; hence, 
it was difficult to evaluate the radiation protection practices objectively, despite the precautions taken.

\section{Conclusion}

We found that the healthcare workers who were exposed to occupational radiation regularly did not use radiation protection equipment sufficiently and that they were not sufficiently trained about radiation and its safety. The magnitude of the risks for healthcare workers has increased in recent years with the increasing frequency of operations under fluoroscopic guidance. For healthcare workers to possess comprehensive knowledge about the ways to protect themselves from the harmful effects of radiation, regular in-service training should be provided, all employees should pay strict attention to the use of dosimeters individually, and the hospital administration should provide a complete array of protective equipment and inspect the implementation of protective measures regularly.

Peer-review: Externally peer-reviewed.

Conflict of Interest: The authors declare that there is no conflict of interest.

Authorship contributions: Concept - N.K.; Design - S.K.; Supervision - N.K., S.K.; Materials - S.K., N.K.; Data collection \&/or processing - S.K., N.K.; Analysis and/or interpretation - S.K.; Literature search - S.K., N.K.; Writing - S.K.; Critical review - N.K., S.K.

\section{References}

1. Zeyrek CT. The Concepts for Safety and Protection in Applications of Ionizing Radiation. Suleyman Demirel University Journal of Natural and Applied Science 2013;17(3):1-9.

2. Yaren H, Karayılanoğlu T. Radyasyon ve insan sağllğ̣ üzerine etkileri. TSK Koruyucu Hekimlik Bülteni 2005;4(4):199-208.

3. Haciosmanoğlu T. Natural and Artificial Radiation Sources and Personal Dose Additives. Nucl Med Se$\min 2017 ; 3: 166-71$.

4. http://www.who.int/ionizing_radiation/medical_exposure/global-initiative Accessed Jan 2, 2018

5. Hall EJ, Brenner DJ. Cancer risks from diagnostic radiology. Br J Radiol 2008;81(965):362-78.

6. Jablon S, Bailar JC 3rd. The contribution of ionizing radiation to cancer mortality in the United States. Prev Med 1980;9(2):219-26.

7. Saygın M, Yaşar S, Çetinkaya G, Kayan M, Özgüner MF, Korucu CÇ. Depression and Anxiety Levels of Radiology Workers. Journal of Health Science Süleyman Demirel Üniversitesi 2011;2(3).
8. Daşdağ S. Ionizing radiations and cancer. Dicle Medical Journal 2010;37(2):177-85.

9. TC Resmi Gazete 05.07.2012. Sağlık Hizmetlerinde Iyonlaştırıcı Radyasyon Kaynakları Ile Çalışan Personelin Radyasyon Doz Limitleri Ve Çalışma Esasları Hakkında Yönetmelik. Resmi Gazete No: 28344

10. Karataşlı M, Özer T. Dozimeters In Business Safety. İstanbul Aydın Üniversitesi Dergisi 2018;10(1):15-31.

11. Kim KY, Cho JH, Lee HK. Analysis of dose measurement other than the radiation protection during the radiographic examination. Springerplus 2014;3:250.

12. Theocharopoulos N, Perisinakis K, Damilakis J, Papadokostakis G, Hadjipavlou A, Gourtsoyiannis N. Occupational exposure from common fluoroscopic projections used in orthopaedic surgery. J Bone Joint Surg Am 2003;85-A(9):1698-703.

13. Lyra M, Charalambatou P, Sotiropoulos M, Diamantopoulos S. Radiation protection of staff in 111In radionuclide therapy-is the lead apron shielding effective? Radiat Prot Dosimetry 2011;147(1-2):272-6.

14. Schueler BA, Balter S, Miller DL. Radiation protection tools in interventional radiology. J Am Coll Radiol 2012;9(11):844-5.

15. Dawson P, Punwani S. The thyroid dose burden in medical imaging A re-examination. Eur J Radiol 2009;69(1):74-9.

16.Zielinski JM, Garner MJ, Band PR, Krewski D, Shilnikova NS, Jiang $\mathrm{H}$, et al. Health outcomes of low-dose ionizing radiation exposure among medical workers: a cohort study of the Canadian national dose registry of radiation workers. Int J Occup Med Environ Health 2009;22(2):149-56.

17. Faulkner K, Harrison RM. Estimation of effective dose equivalent to staff in diagnostic radiology. Phys Med Biol 1988;33(1):83-91.

18. Auvinen A, Kivelä T, Heinävaara S, Mrena S. Eye Lens Opacities Among Physicians Occupationally Exposed to Ionizing Radiation. Ann Occup Hyg 2015;59(7):945-8.

19. Hammer GP, Scheidemann-Wesp U, Samkange-Zeeb F, Wicke H, Neriishi K, Blettner M. Occupational exposure to low doses of ionizing radiation and cataract development: a systematic literature review and perspectives on future studies. Radiat Environ Biophys 2013;52(3):303-19.

20. Singer G. Occupational radiation exposure to the surgeon. J Am Acad Orthop Surg 2005;13(1):69-76.

21. Stoeckelhuber BM, Leibecke T, Schulz E, Melchert $\mathrm{UH}$, Bergmann-Koester CU, Helmberger T, et al. Radiation dose to the radiologist's hand during continuous CT fluoroscopy-guided interventions. Cardiovasc Intervent Radiol 2005;28(5):589-94.

22. Ullman JM. Increasing the usefulness of disposable lead gloves. Radiology 1990;174(2):581. 